\title{
STUDY ON TWO-BODY WEAR BEHAVIOR OF GRAPHENE FILLED E-GLASS FABRIC EPOXY COMPOSITES
}

\author{
D J Akshaykumar ${ }^{1}$, VN Vivek Bhandarkar ${ }^{2}$, M R Haseebuddin ${ }^{3}$ \\ ${ }^{1}$ Post Graduate Student, Department of Mechanical Engineering, Dayananda Sagar College of Engineering, \\ Bangalore - 560078, India \\ ${ }^{2}$ Assistant Professor, Department of Mechanical Engineering, Dayananda Sagar College of Engineering, Bangalore- \\ 560078, India \\ ${ }^{3}$ Assistant Professor, Department of Mechanical Engineering, Dayananda Sagar College of Engineering, Bangalore- \\ 560078, India
}

\begin{abstract}
The paper focuses on the two-body wear behavior of Glass Epoxy $(G-E)$ composites. The composites were prepared by vacuum molding process using glass fiber as reinforcing and epoxy as matrix. And been evaluated by the addition of Graphene used as a filler with 0, 0.2, 0.4, 0.6, 0.8 and 1 by wt \% as a secondary reinforcement in composites using vacuum molding process and the fabrication of composites was carried out at lbar atmospheric pressure and post curing in electric oven. The composites are tested for wear behavior in accordance with ASTM standards. By using pin on disc (POD) equipment at an applied load of 10N, $20 \mathrm{~N}$ and $30 \mathrm{~N}$ for different sliding distances say $(500 \mathrm{~m}, 1000 \mathrm{~m}, 1500 \mathrm{~m})$ and test speeds were constant at 200rpm. The results indicate that the addition of graphene in G-E composite increases the wear resistance considerably with increase in different filler composition.
\end{abstract}

Keywords: wear test, glass fiber, epoxy, graphene, vacuum molding, pin on disc.

\section{INTRODUCTION}

Present day composite materials in production technology and areas of use are continuously increasing due to their good combination of properties, FRP composites are being used particularly in automotive, aircraft industries, manufacture of spaceships and sea vehicles [1-3]. When compared to conventional metallic designs these materials are attractive. They have relatively low density and can be tailored and arranged in sequences to provide high strength and stiffness in direction of high loading [4]. Composite materials consist of reinforcement and resin chosen according to their desired mechanical properties and the application [5]. Epoxy resins generally known as products used in structural components, protective plating and adhesive on account of their very good mechanical properties, electrical characteristics and chemical resistance. When epoxy (LY556) resins are reinforced with high strength E-glass fibers, the product obtained is used in structural application requiring high strength and low weight [3, 6-8]. And commonly they are used as matrix materials, particularly with E-glass fibre reinforcement. Epoxy is an economic material that has high resistant to environmental and chemical resistance. A composite can also be defined as judicial combination of two or more dissimilar materials having different physical and elastic properties in such a way that the resultant material properties are superior to any parental one. Many fabrication methods among which, Vacuum Molding (VM) and hand lay-up (HL) are the most widely used. VM is a widely used molding process for the manufacture of composites with high mechanical properties.
The abrasive wear process was divided into two groups namely two-body wear and three-body abrasive wear. In two body abrasive wear, the wear will be caused by hard particles on one surface which can only slide over the other. The objectives of this study are to investigate the wear properties of woven bi-directional E-Glass Fiber Reinforced polymer composites. The effect of graphene concentration on the specific wear rate and the coefficient of friction is discussed.

\section{MATERIALS AND METHODS}

E-Glass fiber, graphene, mechanical stirring, Vacuum molding.

\subsubsection{Glass Fiber (Fabric/Mat)}

The E-glass fiber was used in this study which was woven into a fabric (bi-direction). The fabrication of composite was $0^{\circ}$ and $90^{\circ}$ and the fabric was cut by $200 \times 150 \mathrm{~mm}$ in dimensions. The thickness of fabric (mat) was $0.28 \mathrm{~mm}$ and weighs $300 \mathrm{~g}$ and density $1.96 \mathrm{~g} / \mathrm{cm} 3$. E-Glass fiber reinforced polymer (GFRP) composites has superior properties like high stiffness, high strength and also low moisture absorption. For the functional and structural application the GFRP composites widely used. Multiple reports showed the positive effect of Graphene addition on the crack propagation resistance of polymer resins. 


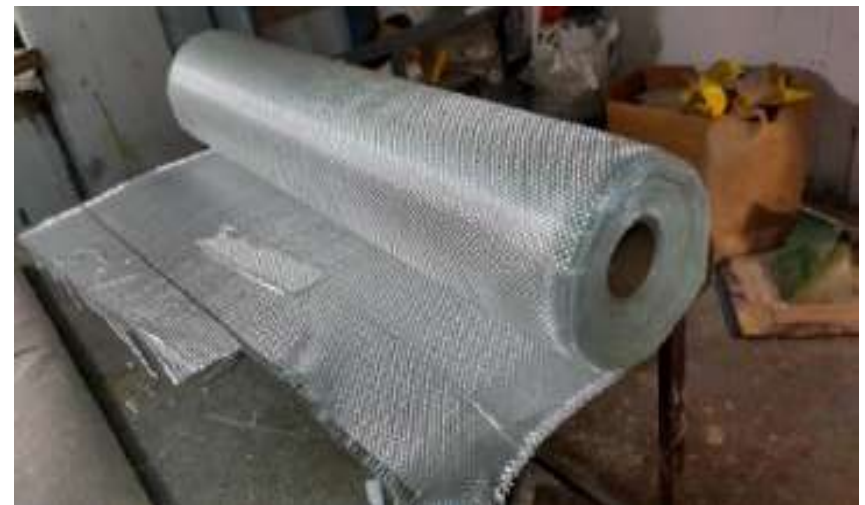

Fig.1. E-Glass fiber

Bi-directional oriented glass fibers are used as a reinforcing material, here LY556 epoxy resin and suitable hardener along with diluents DY02 are used and graphene used as a filler material. The composites made using vacuum molding process.

\subsubsection{Graphene}

The multi layered graphene which was used in this study was in form of nano platelets and the size in $\mathrm{X} \& \mathrm{Y}$ dimensions was 5-10 $\mu \mathrm{m}$ and $\mathrm{Z}$ dimensions it was 3-6nm and density $0.24 \mathrm{~g} / \mathrm{cm} 3$.

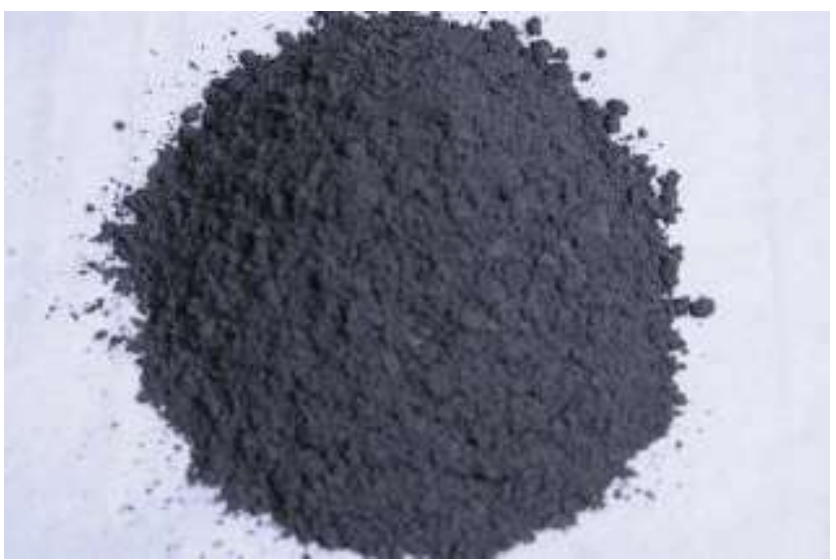

Fig.2. Sample of graphene used.

\subsection{Specimen Preparation}

The process starts with cleaning the surface with acetone which removes the foreign particles. Then vacuum bag sealant is used to keep the composite airtight. Later wax is applied as releasing agent for smooth release of composite from surface. Ten layers of E-glass fiber with bidirectional orientation with required dimensions of $150 \times 200 \mathrm{~mm}$ is placed on release film and epoxy is added with graphene with wt $\%$ ratio mixed with stir method for 30min and then $10 \%$ of epoxy wt the hardener is added and mixed thoroughly and then is applied on each layer of glass fiber placed layer by layer. After 10layers its left for some time say $10-15$ mins so as if suddenly vacuum is applied then the epoxy may get into the vacuum pipe and may damage motor or we should place breather near entry of pipe. Now Teflon cloth is placed on last layer of the composite then fill play is placed on Teflon cloth and then next to fill play the breather is cut according to dimension and placed. Then a plastic sheet which covers the complete composite area including sealant is sealed with hand to overcome air from atmosphere. Then the pipe is placed at one end of composite and then vacuum pressure is set to required say $1 \mathrm{~atm}$ pressure and left it with same for 2hours. After that the vacuum is removed and then post curing is done in heat oven for temperature set around $120^{\circ} \mathrm{C}$ one and half hour.

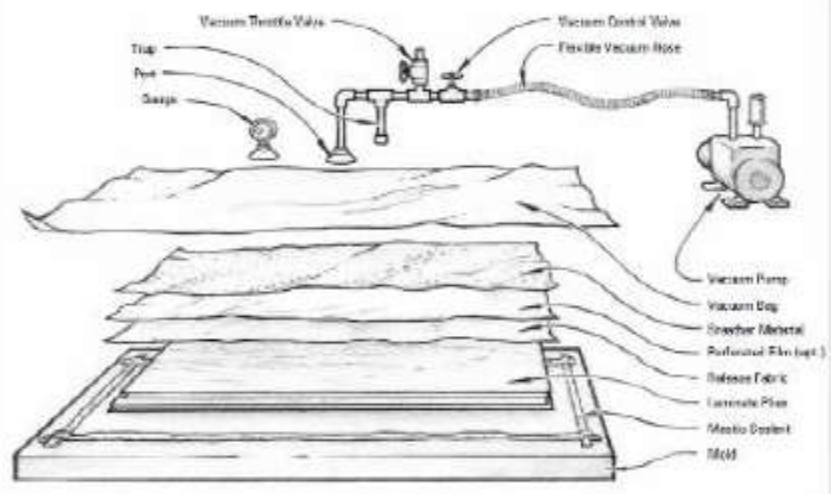

Fig.3. Vacuum Molding setup

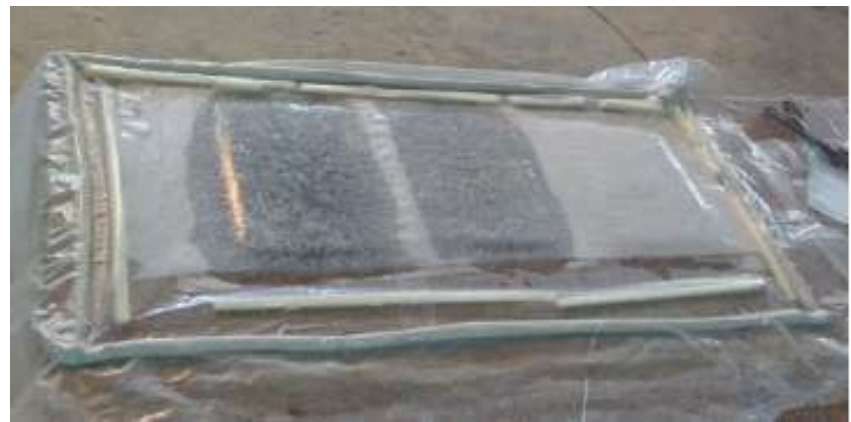

Fig.3. shows the vacuum molding process carried out.

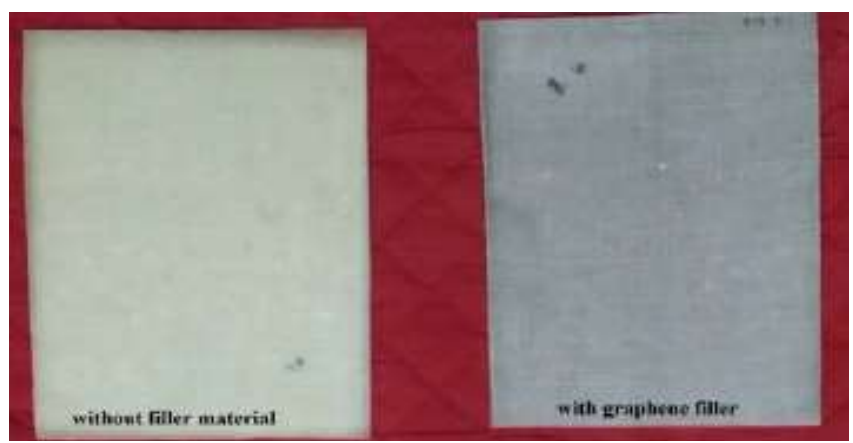

Fig.4. Fabricated composites.

\subsection{Two Body Wear Test}

In this study pin on disc equipment was used, were circular disc of track radius $30 \mathrm{~mm}$ and the specimen of diameter $8 \mathrm{~mm}$, and the specimen which was cut to $10 \times 10 \mathrm{~mm}$ dimension was placed to the specimen holder and it has a load connected to holder through pulley arrangement and acts as point load when load is placed on pan. While conducting test the specimen should be set at 200rpm and test time should be set, later the POD MAGVIEW-2009 software on computer is set with input data as load, track radius, rpm and pin dia. The specimen is in contact with 
circular disc and the results are extracted and Graph has been plot for same.

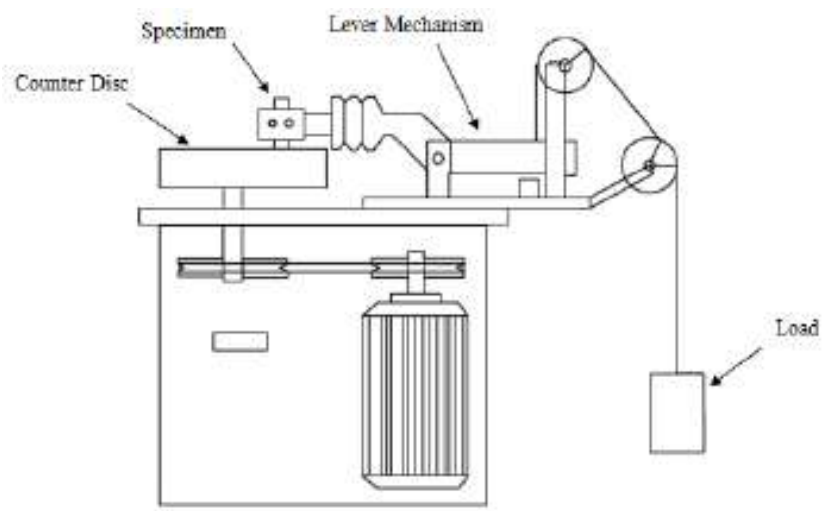

Fig.5. Schematic diagram of wear test machine.

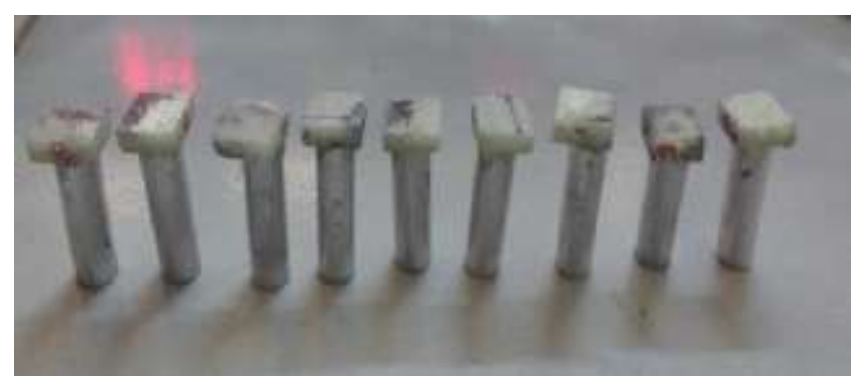

Fig.6. Wear Test Specimens after test.

\section{RESULTS AND DISCUSSION}

The Two Body Wear Test specimens were prepared as per the required dimensions and the influence of Graphene filler on the wear behavior was measured. The two body wear test, using a Pin on Disc test rig, is done as per ASTM standards. Figure 7, 8 \& figure 9 shows the results of wear rate for different sliding distances for $10 \mathrm{~N} 20 \mathrm{~N}$ and $30 \mathrm{~N}$ loads. As the Sliding distance increased the wear rate also increased. Also when the load is applied the wear rate increased. This is due to energy barrier created at the junction of the surface. When the lower loads are applied then the friction is not sufficient to wear the surface and by applying the higher loads, wear on circular disc surface was more, hence the wear rate was high.

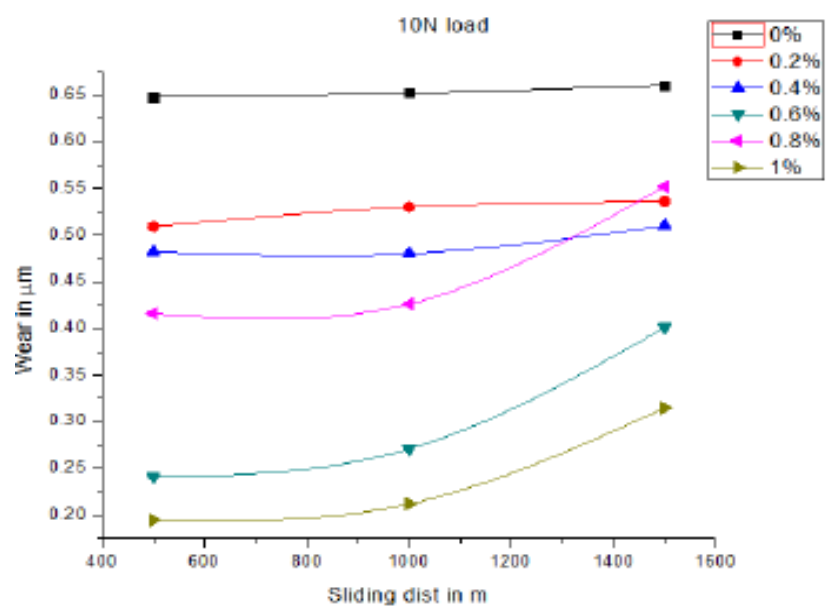

Fig.7. Wear rate for $10 \mathrm{~N}$ load with increasing sliding dist.

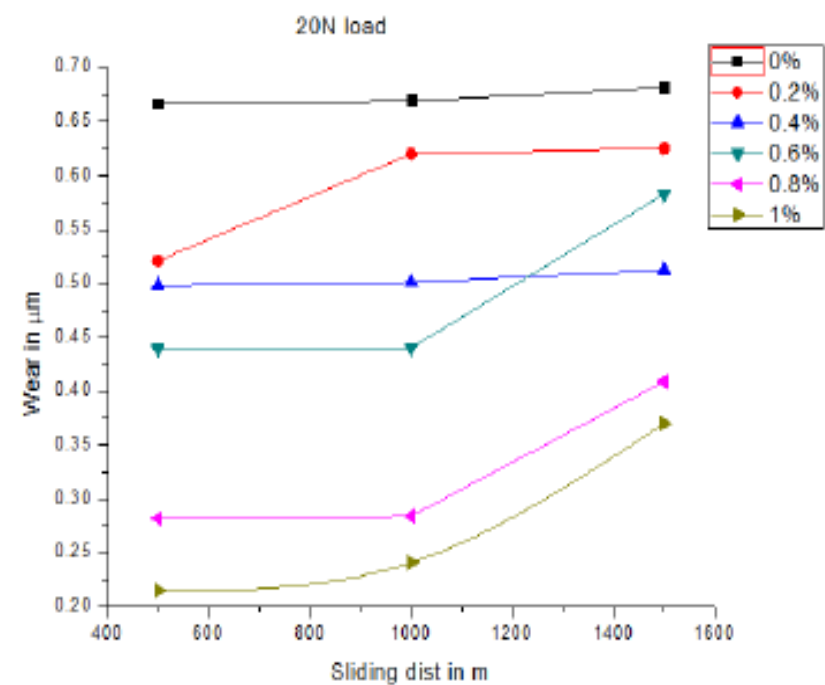

Fig.8. Wear rate for $20 \mathrm{~N}$ load with increasing sliding dist.

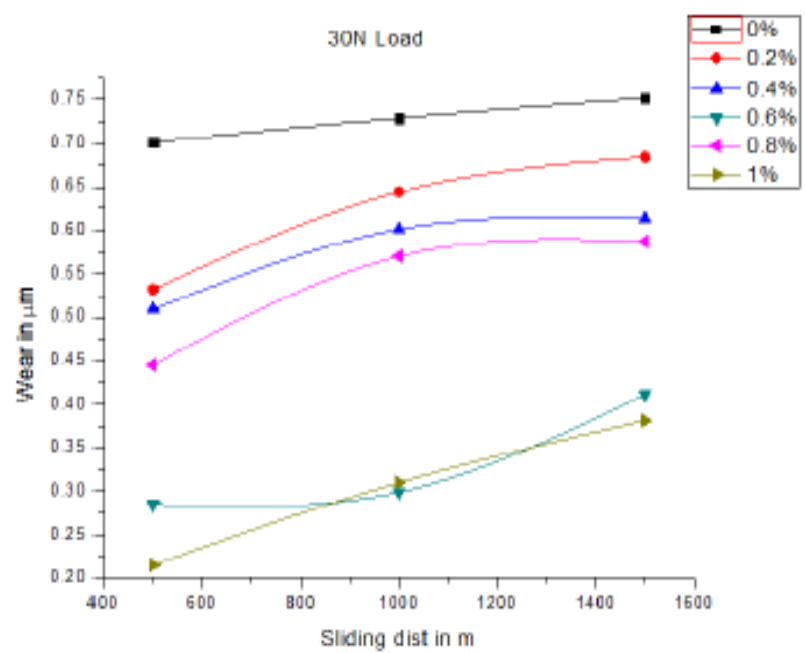

Fig.9. wear rate for $30 \mathrm{~N}$ load with increasing sliding dist.

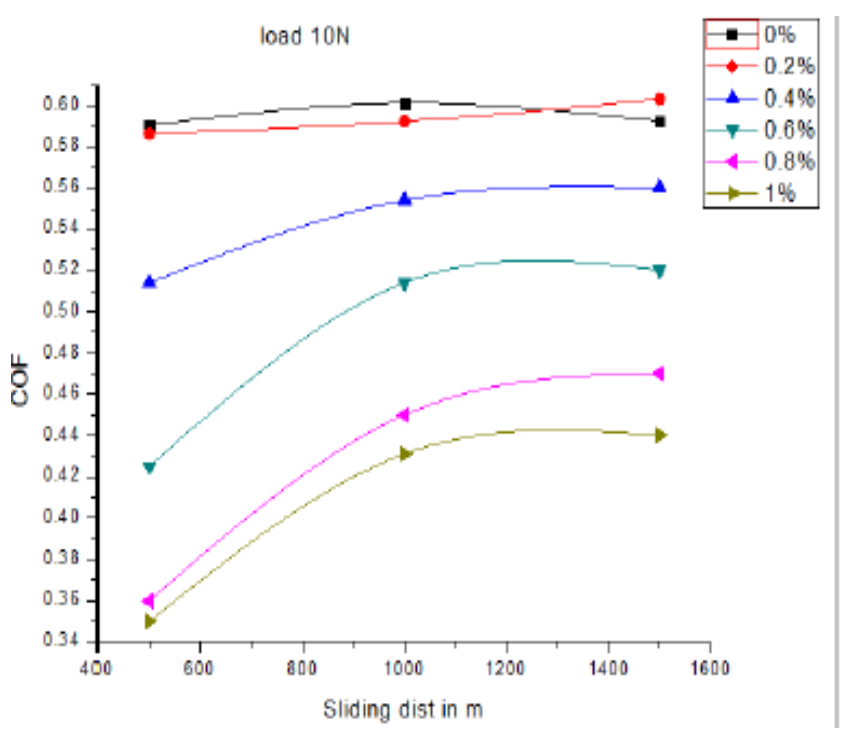

Fig.10. COF Vs sliding dist for constant $10 \mathrm{~N}$ load. 


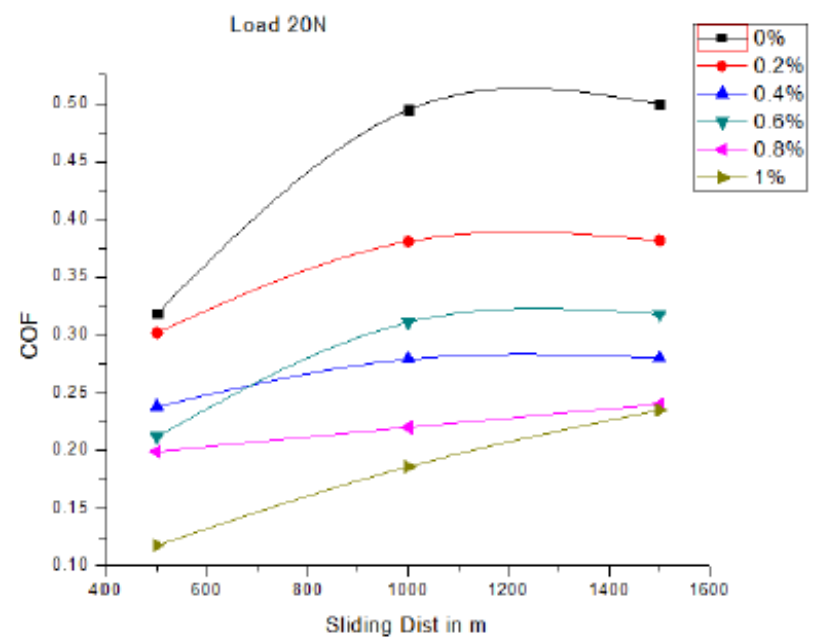

Fig.11. COF Vs sliding dist for constant 20N load.

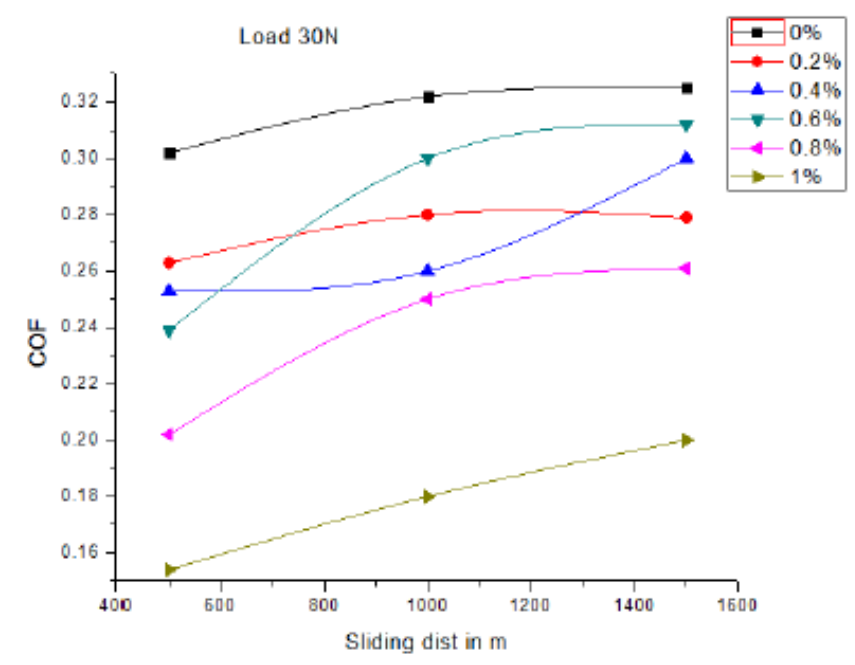

Fig.12. COF Vs sliding dist for constant 30N load.

\section{CONCLUSION}

- It is observed from the results tabulated with the increasing sliding distance the wear rate increases.

- $\quad$ The composites without graphene filler shows higher wear rate compared to composites with graphene filler with 1 weight $\%$.

- Also it is observed that increase in graphene contain in composite is showing reduction in wear behavior, this may be due the self-lubricating properties of graphene.

- $\quad$ Pin on disc were carried out at $10 \mathrm{~N}, 20 \mathrm{~N}, 30 \mathrm{~N}$ loads in all the 3 graphs plotted similar trend is observed that is with increase in filler contain in composites wear reduces.

- $\quad$ Also the COF was reduced for the tested composites and similar trend is observed, the COF reduces with increase in filler contain and best results were found for $1 \mathrm{wt} \%$ of graphene filler.

\section{REFERENCES}

[1]. Collyer AA. Rubber toughened engineering materials. Chapman Hall, 1994.
[2]. Duman S, . The Study of the Wear in the Composite Materials. Master thesis, Firat University, Graduate Scholl of Natural and Applied Sciences, Elazıg . Turkey, 1999.

[3]. El-Tayep NS, Gadelrap RM. Friction and wear properties of Eglass fiber reinforced epoksi composites under different sliding contact conditions. Wear 1996;192:112 - 17.

[4]. Chand N, Naik A, Neogi S. Three-body abrasive wear of short glass fibre polyester composite. Wear 2000;242:3846.

[5]. Piggot MR. Load-bearing fibre composite. Pergamon Press, 1980.

[6]. Kishore, Sampathkumaran P., Seetharamu S., Vynatheya S., Murali A., Kumar RK. SEM observations of the effects of velocity and load on the sliding wear characteristics of glass fabric- epoxy composites with different fillers. Wear 2000;237:20 -27.

[7]. Kishore Sampathkumaran P, Seetharamu S, Murali A, Kumar RK. On the SEM features of glass-epoxy composite system subjected to dry sliding wear. Wear 2001;247:208 13.

[8]. Pilato LA, Michno MJ. Advanced composite materials. Springer- Verlag, 1994. 